Daimon. Revista Internacional de Filosofía, $n^{\circ} 83,2021$ pp. 231-248

ISSN: 1130-0507 (papel) y 1989-4651 (electrónico)

http://dx.doi.org/10.6018/daimon.383031

Las obras se publican en la edición electrónica de la revista bajo una licencia Creative Commons ReconocimientoNoComercial-SinObraDerivada 3.0 España (texto legal). Se pueden copiar, usar, difundir, transmitir y exponer públicamente, siempre que: i) se cite la autoría y la fuente original de su publicación (revista, editorial y URL de la obra); ii) no se usen para fines comerciales; iii) se mencione la existencia y especificaciones de esta licencia de uso.

\title{
Sufrimiento, Holocausto y memorias colectivas en el pensamiento histórico de Hayden White*
}

\author{
Suffering, Holocaust, and Collective Memories \\ in the historical thought of Hayden White
}

AITOR MANUEL BOLAÑOS DE MIGUEL ${ }^{* *}$

\begin{abstract}
Resumen: Este texto ofrece una reflexión sobre una cuestión de gran trascendencia para el pensamiento histórico-filosófico de comienzos del siglo XXI: el lugar que ocupan las víctimas y su sufrimiento en una reconsideración epistemológica de las ciencias sociales, del pensamiento humanista y de la propia disciplina historiográfica. Para ello, este artículo ofrece un análisis de la obra de Hayden White, una obra que concede un papel trascendenal a las memorias colectivas de las víctimas, así como a su sufrimiento. Y todo ello con una intención crítica y ético-política, imprescindible para el progreso científico y social.

Palabras clave: Hayden White, Sufrimiento, Memorias Colectivas, Víctimas, Historia.
\end{abstract}

\begin{abstract}
This text offers a reflection on a question of great importance for the historicalphilosophical thought of the beginning of the 21st Century: the place occupied by the victims and their suffering in an epistemological reconsideration of the social sciences, of humanist thought and of the historiographic discipline itself . For doing this, this article offers an analysis of Hayden White's oeuvre, a work that grants a transcendental role to the collective memories of the victims, as well as to their suffering. And all this with a critical and ethical-political intention, essential for scientific and social progress.
\end{abstract}

Keywords: Hayden White, Suffering, Collective Memories, Victims, History.

Recibido: 07/06/2019. Aceptado: 22/09/2019.

* Este artículo se inscribe en el Proyecto de I+D "Sufrimiento social y condición de víctima: dimensiones epistémicas, sociales, políticas y estéticas” (FFI2015-69733-P), financiado por el Programa Estatal de Fomento de la Investigación Científica y Técnica de Excelencia. Quiero dar las gracias a Reyes Mate y a J.A. Zamora por sus críticas y sugerencias, precisas y enriquecedoras.

** Profesor contratado doctor de CC. Políticas y Gestión Pública (Universidad Internacional de La Rioja). Contacto: aitor.bolanos@unir.net. Líneas de investigación: Historiografía, Filosofía de la Historia, Memorias Colecticas, Justicia Transicional, Políticas de la Memoria y Filosofía política. Aitor Bolaños (coord..). Metahistoria: 40 años después: ensayos en homenaje a Hayden White, Logroño: Siníndice Editorial, 2014; Aitor Bolaños, "Memorias colectivas y memorias de las víctimas: la centralidad del sufrimiento individual y social en los mecanismos de Justicia Transicional”, Revista Insurgencia, 4,1, 2018, pp. 60-86. 
Dedicado a la memoria de Hayden White

\section{Palabras previas}

En este artículo pretendo reflexionar sobre una cuestión de gran trascendencia para el pensamiento histórico y filosófico de comienzos del siglo XXI: el lugar que ocupan las víctimas y su sufrimiento en una reconsideración epistemológica de las ciencias sociales, del pensamiento humanista y de la propia disciplina historiográfica. Y todo ello con la intención de analizar la obra de un autor que tanto ha hecho por situar en el centro del debate sobre el pasado las cuestiones más puramente políticas y éticas, además de las teóricas o metodológicas.

En primer lugar, y en relación con el Holocausto, voy a recordar la distinción que hace Hayden White entre hecho y acontecimiento, que nos ayudará a entender la clase de historicismo lingüístico y textual que practicaba nuestro autor, y que tantos debates y discusiones ha provocado. En segundo lugar, me voy a centrar en lo que White denomina "acontecimiento modernista" ("Modernist Event") porque tiene una estrecha relación con el fenómeno del Holocausto y, por extensión, con nuestros intentos por comprender a las víctimas y por representar(nos) su dolor, su sufrimiento y sus traumas. Y ello porque, entre otras razones, el Holocausto se ha transformado en un acontecimiento traumático fundamental para entender la historia y la identidad del mundo contemporáneo. De hecho, como ha escrito Fritzsche, “el nacionalsocialismo propinó un golpe traumático al pensamiento occidental" y aunque es verdad que "la información sobre la guerra que los nazis libraban contra los judíos se conocía y acumulaba, no era fácil transformarla en conocimiento sobre el genocidio" (2009, 21-2). Y, de hecho, esa transformación es una tarea que ha llevado varias décadas de luchas historiográficas, memorísticas e identitarias, desde la década de los cuarenta y hasta la actualidad, $\mathrm{y}$, por su puesto, de una forma no lineal sino con vaguedades, retrocesos y ondulaciones. Y, en tercer lugar, voy a examinar algunas reflexiones de White sobre la relación entre las memorias colectivas, las víctimas y la historiografía, con la intención de comprender lo que él llama "el pasado práctico" ("the Practical Past").

\section{Los hechos son una cosa, los acontecimientos otra}

Este apartado proporciona un instrumento para contextualizar mi análisis del compromiso político de la historiografía postmoderna en una representación del Holocausto que intente hacer justicia a su complejidad y a sus variadas dimensiones, incluidas las políticas, las éticas y las metafóricas. Así, entender el Holocausto incluye pensar "la Shoah" como metáfora del exterminio masivo de millones de personas; como metáfora del genocidio judío, gitano y eslavo; como metáfora de la violencia política extrema (llevada a cabo por parte del aparato estatal Nazi); como metáfora del "universo concentracionario", de los campos de concentración y de exterminio absolutos; como metáfora, por tanto, del sufrimiento y de la deshumanización total; como metáfora del acontecimiento histórico "sublime", que se escapa a las técnicas de la representación historiográfica académica positivista tradicional; o como metáfora del mal "originario" de nuestra post-modernidad (tan importante para la reflexión 
crítico filosófica contemporánea, desde el famoso dictum Adorniano o la "Todesfuge", de Paul Celan, en adelante). En este último sentido, por ejemplo, estoy de acuerdo con White cuando sugiere que comprender la post-modernidad implica, necesariamente, comprender un "acontecimiento modernista" como el Holocausto, hacerlo inteligible y, por tanto, vislumbrar su espeluznante y aterrador significado. Y ello porque el Holocausto, en general, y Auschwitz, en particular, se han convertido en símbolos del fin del proyecto ilustrado y humanista de la modernidad, en metáforas de un derrumbe civilizatorio paradójico y sin parangón.

Por otro lado, me gustaría recordar que algunas de las características de la historiografía postmoderna no son privativas de esta corriente intelectual. White considera que la postmodernidad es una concreta cosmovisión histórica, basada en una concepción específica de la naturaleza y de los usos de la historia $(2011,517) .{ }^{1}$ En un sentido, la postmodernidad continúa el proyecto de la modernidad de desmitificar y de laicizar nuestro conocimiento del pasado, subrayando la naturaleza constructivista, ideológica y textual de nuestras representaciones historiográficas sobre el mismo. Así, la "postmodernidad reconoce que la 'realidad' es tanto lo que se descubre en los documentos históricos como lo que se construye en el discurso" $(2011,528)$. En este sentido, la postmodernidad pone el énfasis "en que, cuando se trata de estudiar el pasado el historiador debe aceptar la responsabilidad de la construcción de lo que previamente pretendía tan solo haber descubierto" $(2011,518)$. Y es esta situación (frente a la situación anterior, donde se predicaba la objetividad de la historiografía tradicional), la que crea distintas ansiedades e inseguridades.

En primer lugar, ansiedades textuales. Y es que el textualismo es el corazón de la postmodernidad. Por textualismo, White considera "la idea de que el texto escrito constituye el paradigma de la cultura, que la mejor forma de entender la producción cultural es a partir del modelo de la producción textual y que la mejor manera de interpretar la cultura es a través de prácticas de lectura análogas punto por punto a las de la lectura de un texto" $(2011,526)$. Pero, claro, hay que recordar que esta concepción textualista de la cultura se basa en la idea de que un texto nunca está de acuerdo consigo mismo, es siempre un tejido problemático de tropos y figuras, un artefacto lingüístico inestable y libre. Algo que nunca está fijo. Como los acontecimientos históricos.

Por eso, se puede considerar, no sin cierta polémica historicista, que el postmodernismo, en su relación con el post estructuralismo, es, en buena medida, una respuesta al Holocausto, como demuestran las obras de Derrida, Lyotard o del propio White (Eagleston, 2008, 2). De hecho, White apunta la relación entre la clase de historia que él defiende y la genealogía foucaultiana (White, 2011, 532). Derrida, por ejemplo, que llamaba al Holocausto el "quema-

1 En este artículo uso el término "modernidad" como sinónimo del proyecto ilustrado, humanista y de progreso de los siglos XVIII, XIX y comienzos del XX, Por otro lado, no hay que confundir esta expresión con otro uso del término "modernidad", que es el que se refiere a un conjunto de movimientos artísticos que han inspirado buena parte de las vanguardias de comienzos del siglo XX y, también, buena parte de las propuestas críticas de los autores postmodernos. Este segundo uso tendría las características que autores como Peter Gay le han asignado al término "modernidad". Por otro lado, uso el término postmodernidad como sinónimo de un movimiento intelectual crítico respecto de las contradicciones y de los excesos de ese proyecto ilustrado, en el sentido en el que autores como Keith Jenkins y Alun Munslow le han asignado (aunque, en algunas ocasiones, dicho término se solapa con la mera descripción de un momento histórico-cultural que acontece tras la modernidad, fundamentalmente después de la $2^{\text {a }}$ G.M., en el sentido en que autores como Fredric Jameson han estudiado y criticado). 
todo", "el abrasamiento", "la cremación final", "la ceniza universal", siguiendo a Blanchot y a Celan, pensaba que, en realidad, "hay un holocausto para cada fecha", en alguna parte del mundo, en cualquier instante (Derrida, 2002, 78 y 104; Derrida, 2011, 231). Por su parte, Lyotard se ha encargado de subrayar, en varios de sus escritos, la fenomenología sublime del Holocausto, su naturaleza "excesiva", lo inconmensurable del sufrimiento que ha producido (1997). La historiografía de inspiración benjaminiana, por otro lado, incorpora también un alto grado de compromiso moral, reflexividad crítica y reconocimiento de la complejidad, algo que la puede relacionar con la historiografía postmoderna. Lo mismo que pretende la historiografía whiteana. Precisamente, White sugiere que "el Holocausto no fue el primer crimen contra la humanidad que haya tenido lugar, si bien es, dada la naturaleza de quienes lo perpetraron, el más execrable moralmente" $(2011,551)$.

Sin embargo, lo que resaltaré en este artículo es la relación que existe entre los elementos analíticos, críticos y reflexivos; entre las implicaciones subjetivas del historiador y su respuesta ética ante el acontecimiento; entre los elementos fácticos, ficcionales (el cómo se cuenta lo que se cuenta) y metaficcionales (la reflexión crítica sobre la mejor forma de contar y/o representar lo que se cuenta y/o representa); y, en suma, entre los elementos declarativos y discursivos (afirmaciones sobre el pasado y elementos retóricos y literarios) y los elementos metadiscursivos (los elementos que desvelan la estructura de la obra y hacen partícipe al lector y al espectador en la construcción de "su" significado).

En relación con la distinción entre acontecimientos y hechos, conviene recordar que el historiador no puede observar al pasado para comprobar cómo es. O, como nos recuerda repetidamente White, el pasado está ausente, ya no existe. No es como el presente, no puede ser observado. De aquí proviene la clásica distinción entre "acontecimiento" y "hecho" (o entre el pasado y la Historia; o entre historia e historiografía). No hay que confundir al uno con el otro. Igual que no hay que confundir al pasado con los libros de historia ni con las películas históricas. Los "acontecimientos" (o "eventos") ocurren, suceden, en un espacio y un tiempo material, mientras que los "hechos" son constituidos por las descripciones lingüísticas que elaboran, entre otros, los historiadores: no tienen realidad fuera del lenguaje. $U$ otra forma de decirlo: "mientras los acontecimientos pueden haber tenido lugar, su representación como hechos los dota de todos los atributos de los temas literarios e, incluso, míticos", es decir: ficcionales (White, 2011, 530). Como decía Mink, "un evento histórico es aquel que puede ser descrito verazmente de modo que sirva como elemento de una narrativa" (White, 2010a, 138). Y es que, como ha dicho Jameson, nuestro sentido de la realidad pasada siempre toma la forma de una narrativa².

White argumenta que "cualquier intento de describir o de representar la realidad [incluída, especialmente, la pasada] en lenguaje debe enfrentar el hecho de que no existe un lenguaje literal, de que todo lenguaje es en su 'esencia' figurativo" $(2011,529)$. Un hecho es, según White, un fenómeno discursivo, "un enunciado acerca de un acontecimiento en la forma de una predicación", es decir: una descripción que ya no es simplemente declarativa sino figurativa o conceptual (como en el "realismo figural" historizado por Auerbach) $(2003,53)$. Como ha repetido White, la figuración produce estilización, que canaliza nuestra atención

2 Vid. la entrevista que le hizo Ramón del Castillo en la Fundación March: https://www.march.es/ videos $/ \mathrm{p} 0=5751 \& \mathrm{l}=1$ (minuto 32 aproximadamente). 
hacia el autor y, menos, hacia la realidad pasada. La figuración genera una "perspectiva", en el lector, sobre el referente del discurso, y al destacar una perspectiva en especial, necesariamente se obvian otras. El resultado es que se reducen u opacan determinados aspectos de los sucesos acaecidos en el pasado. Como ha escrito el propio White, "no history, visual or verbal, "mirrors" all or even the greater part of the events or scenes of which it purports to be an account, and this is true even of the most narrowly restricted "micro-history." Every written history is a product of processes of condensation, displacement, symbolization, and qualification exactly like those used in the production of a filmed representation. It is only the medium that differs, not the way in which messages are produced" $(1988,1194)$.

White resume su postura con la siguiente afirmación: "the fact is a statement about the event". ${ }^{3}$ Mientras los acontecimientos o eventos ("events") ocurren y pueden ser probados a través de los documentos y de los testigos, ${ }^{4}$ los hechos ("facts") son elaborados imaginativamente por el historiador, que los mantiene en su pensamiento hasta que predica algo de ellos, es decir, hasta que les da forma discursiva en una representación historiográfica (textual o gráfica). Como resume Tozzi, "la descripción involucra un elenco de atributos del evento, la predicación en cambio involucra incluirlo en alguna clase y nominarlo de manera apropiada" (White, 2010a, 23). Es decir, los hechos son construcciones de los historiadores en la medida en que "un evento no puede ingresar en la historia, hasta que sea establecido como un hecho" (White, 2010a, 129). Mientras los eventos "suceden" (o han sucedido), los hechos "se dicen". En este sentido, Barthes afirmaba que los hechos solo pueden tener una existencia lingüística (y/o visual) $(1984,175)$. Por otro lado, no todos los eventos acceden a la categoría de hechos: no todo el pasado, no todo lo que ha acontecido en el pasado, es representado. Es decir, no todos los eventos son descritos, explicados e interpretados. La historiografía, como práctica social, selecciona aquellas porciones del pasado, aquellos eventos, que van a ser transformados en hechos mediante la aplicación de los correspondientes pasos metodológicos y científicos aceptados en cada etapa de desarrollo de la disciplina.

El problema implicado en esta distinción es que, a veces, el historiador olvida que una simple crónica de los acontecimientos es ya, de por sí, una interpretación de los mismos; es decir, una crónica ordenada y cronológica de los acontecimientos acaecidos en un momento del pasado ya es, de por sí, una selección y una jerarquización de los mismos: lo que los convierte en hechos (significativos, por tanto). Y esta distinción tiene la máxima importancia a la hora de reflexionar y de representar sucesos tan espinosos como el Holocausto, sucesos donde la distinción, aparentemente diáfana, entre hecho y acontecimiento, se problematiza hasta casi hacerla dudosa. En realidad, es lo que ocurre con cada acontecimiento del pasado pero White sugiere, como veremos, que el tipo de experiencia que suscitan los acontecimientos modernistas problematiza todavía más este tipo de disonancia gnoseológica habitual entre los propios "acontecimientos" (y los documentos) y los "hechos" (nuestras representaciones). Como ha escrito Paul, "modernist events blurred the distinction between event (in reality) and fact (in discourse)" (2011, 133).

3 "Hayden White on the Distinction Between Facts and Events", https://www.youtube.com/ watch?v=Rf0qCabqQU0 (15 de abril de 2018).

4 Es lo que LaCapra denomina los aspectos "documentarios" del texto historiográfico, que los sitúa en términos de sus dimensiones fácticas o literales (LaCapra, 1983, 30). 
En este punto, White nos habla de una distinción que tiene interés historiográfico: conceptos como el "Feudalismo", el "Renacimiento", la "Segunda Guerra Mundial" o el "Holocausto" no son más que figuras, esquemas, "conceptos imprecisos", interpretativos, basados en el entendimiento de una realidad diferida, virtual y "archivada" (documental y monumentalmente). White escribe que estos sintagmas no son sino nombres que asignamos a diferentes partes de un continuum, para crear diferencias en esa misma continuidad, partiendo de la base de que un evento nunca es la totalidad del proceso o la estructura de la que forma parte (2011, 519). Lo que se discute en estos casos es la naturaleza de estos hechos, su significado, su alcance, su impacto, su novedad relativa, así como lo que es capaz de revelar de la sociedad y del momento en los que tuvo lugar. Martin Jay, en un diálogo con White, afirma que el Holocausto es "una entidad conceptual post facto, que no se utilizaba en su momento, que ningún individuo presenció jamás, y cuya verdad o cuyo sentido", independientemente del significado que asignemos a estos dos conceptos, no brota de la acumulación de todos los testimonios individuales de las personas implicadas geográfica e históricamente (Friedlander, 2007, 165).

Una de las cuestiones que subraya la historiografía postmoderna es la dificultad de representar el pasado, en general, así como acontecimientos límite como el Holocausto, en particular, debido a la complejidad de las experiencias vividas por los protagonistas, así como a la extraña parcialidad de los documentos y testimonios disponibles. Además, como escribe Frietzsche, "la violencia de los nazis fue tan excesiva y su sensación de estar por encima de la moral convencional tan completa que ante ellas cualquier intento de explicación vacila" $(2009,12)$. Y una conciencia preclara sobre esa vacilación es la que está detrás de buena parte del escepticismo epistemológico y del relativismo moral de la historiografía postmoderna. El propio White escribió que "nosotros los posmodernos somos serios respecto de nuestra necesidad de significado, aun siendo científicamente irónicos acerca de la posibilidad de encontrar alguna vez significado en el cúmulo de cosas que llamamos realidad [y pasado]" (2010a, 174).

Lo importante en esta distinción ontológica entre hechos y acontecimientos es si "un evento dado cualquiera es asimilable a uno u otro de los sistemas de conocimiento recibidos y disponibles en una determinada comunidad, o si requiere una revisión o incluso un total abandono del sistema previamente considerado como capaz de identificar, clasificar y determinar adecuadamente a un evento" (White, 2010a, 135). En suma, una representación historiográfica puede ser literalmente "verdadera" en la medida en que es fácticamente fiel a los hechos representados, mientras que es figurativamente "verosímil" en la medida en que la narración o la trama elegida es adecuada para (y/o éticamente responsable respecto de) la representación de los hechos del pasado en cuestión (2010a, 84). Como ha escrito Langer, una buena representación del Holocausto ha de mostrar tanto "la verdad literal" del mismo como "la realidad imaginativa" acerca de tal monstruoso evento $(1975,22)$. En resumen, representar el pasado requiere tanto información verídica como una ficción responsable.

\section{El acontecimiento modernista y la representación del sufrimiento}

En varios textos, White reflexiona sobre lo que denomina "acontecimiento modernista". Es decir, acontecimientos históricos que han sido posibles debido a las caracteristicas del proyecto filosófico y cultural de la modernidad, con su creencia absolut(ist)a en las ideas de razón, libertad, sujeto, identidad y progreso. Pero acontecimientos modernistas, también, 
entendidos como acontecimientos de una escala inimaginable, incluso "límite", con una serie de características y una naturaleza que los hacen "propios" (es decir, característicos) del siglo XX. El acontecimiento modernista, dice White, "viene a cambiar aquello que nosotros llamamos evento histórico. Podemos interpretarlo, pero de innumerables formas. Solo podemos interpretarlo porque no podemos clasificarlo por género y especie". ${ }^{5} \mathrm{Al}$ intentar describir, explicar e interpretar esta clase de eventos (su historia, cómo se han originado, cuáles son sus consecuencias), nos encontramos con ciertas dificultades y problemas y las estrategias que los historiadores han usado, tradicionalmente, para representar el pasado, aparecen como insuficientes. De hecho, "a genuinely novel event would be one for which you could not use the principles of explanation that you have become comfortable with in dealing with those events that you felt that you could provide an explanation for" (White, 2009, 74). Los acontecimientos modernistas son como monstruos a los que nos tenemos que enfrentar, en el sentido de que parecen deformes, inhumanos, bestiales y, por supuesto, sublimes.

Así, White considera que la consciencia postmoderna surge, en parte, como una respuesta a este tipo de acontecimientos específicamente modernos del siglo XX. La conciencia histórica desarrollada a lo largo del siglo XIX y comienzos del siglo XX "no cuenta ni con las categorías ni con las técnicas representacionales que exije la efectiva historización de estos acontecimientos" $(2011,520)$. Hay un "salto cuántico", dice White, o un "cambio radical”, en nuestra consciencia histórica tras la modernidad, llámese postmodernidad o como se quiera. Aquí aparece una extraña paradoja puesto que White ha defendido, en general, la idoneidad de la narración historiográfica pero advierte que la narrativización, igual, no es adecuada para la representación de acontecimientos como el Holocausto, que muestran una evidente inestabilidad ontológica. De hecho, White ha sugerido la elaboración de experimentos historiográficos no narrativos o, incluso, anti narrativos, para la representación de este tipo de acontecimientos, que se hallan cargados de una enorme emotividad. Como escribe Tozzi, "la antinarrativa modernista es ese discurso que justamente se hace cargo de la imposibilidad de discriminar la experiencia por un lado y la representación por el otro" (White, 2010a, 18).

Pues bien, entre este tipo de acontecimientos modernistas estarían, por ejemplo, las dos Guerras Mundiales, la Gran Depresión y, por supuesto, el Holocausto (White, 1995; Paul, 2011: 145). White considera que todos los acontecimientos históricos son, por definición, únicos y diferentes entre sí. Todo acontecimiento es singular. También los modernistas. Como toda persona es singular y diferente a las demás, aunque todos tengamos diversas características compartidas. De esta forma, como Bauman, White considera que el Holocausto participa de una naturaleza dialéctica, "de singularidad y normalidad" (Bauman, 1997, 28 y 119), lo cual es la característica más importante de este acontecimiento en relación con otros fenómenos modernos. La cuestión fundamental sobre los "acontecimientos modernistas" (como el Holocausto) no consiste en establecer que dichos acontecimientos han tenido lugar sino en establecer su naturaleza, su significado, su novedad relativa, "el alcance e intensidad de su impacto" así como "lo que revela respecto de la sociedad en la que tuvo lugar" (White, 2010a, 130).

Por muy violento, cruel y devastador que haya sido, el Holocausto no es un fenómeno totalmente único e incomparable. Es un fenómeno singular pero no es único. Si lo fuera,

5 Gilda Bevilacqua, "Entrevista a Hayden White", https://www.revistahumo.com.ar/humo/entrevista/entrevistahayden-white-puede-haber-una-historia-conceptos-nunca-concepto-historia/ (10 de abril de 2018). 
no hubiera podido ser juzgado en Nuremberg. De hecho, el término jurídico "genocidio" surgió en la época para intentar categorizar algunas de las características de lo que los nazis llamaron eufemísticamente "la Solución Final de la cuestión judía" (la Shoah, desde el punto de vista de las víctimas) y, así, poder "tipificarlo" como comportamiento delictivo. Durante los Juicios de Nuremberg, al Holocausto se le trató como un ejemplo de genocidio; con unas características muy particulares, eso sí, y de unas proporciones nunca vistas. Por otro lado, en los debates de las últimas décadas sobre los distintos niveles de responsabilidad durante el Holocausto, historiadores como Mayer han intentado situar el "judeocidio" en una estrategia más amplia del Tercer Reih contra todos sus "enemigos". En concreto, en un plan, más o menos sistemático, de acabar con el pueblo soviético, que representaba un conglomerado de tres de los "grupos raciales" mas odiados por los nazis: los eslavos, los comunistas y los propios judíos (1988).

White afirma que "una noción modernista de evento presupone no solo un nuevo tipo de evento (tales como el ataque a las Torres Gemelas y el calentamiento global), sino también, como un resultado de la revolución de los medios, nuevos modos de percibir, observar o clasificar el evento. El evento modernista, entonces, es doblemente nuevo: en sí mismo [considerado] y en los medios de comunicación disponibles para su observación (o experimentación) [es decir, para las víctimas y para los espectadores e historiadores]". ${ }^{6}$ Como afirma el propio White, "the modernist event is precisely that event that belies the conventional conception of history as containing only those events that can be explained" $(2009,74)$.

Por tanto, los acontecimientos modernistas tienen una característica extra particular: y es la inmediatez con la que ocurren así como la rapidez con la que son registrados a través de los medios de comunicación de masas. Es decir, el espectador (el historiador, por ejemplo) los observa casi inmediatamente, casi según están sucediendo. Sus efectos de presencia surgen a la misma vez que aparecen los efectos de sentido asociados a nuestros intentos por representarlos. Los acontecimientos modernistas diluyen la tradicional separación histórica entre el pasado y el presente y difuminan, así, la tan defendida "distancia histórica", tras la que siempre se ha pertrechado el historiador tradicional. De esta forma, uno se puede plantear que la principal característica de los acontecimientos modernistas no es tanto su naturaleza como su cercanía espacio-temporal (Korhonen, 2006, 65). No por casualidad, estas reflexiones historiográficas se producen en un momento en el que las teorías de Einstein sobre "la relatividad especial" del contínuo espacio-tiempo y sobre "el presente extenso" se están popularizando entre los científicos sociales (Rovelli, 2016, 66 y ss.).

En relación con lo anterior, los acontecimientos modernistas producen un efecto interesante: para las personas directamente involucradas en dichos acontecimientos, su significado permanece indeterminado, confuso. También para los observadores. El círculo hermenéutico que va de las partes al todo y de éste a cada una de las partes, experimentadas o documentadas, no se cierra con facilidad. O no se puede cerrar, en todo caso. De hecho, estos acontecimientos no se prestan para su descripción o explicación en los términos habituales de la historiografía tradicional, basada en la idea de que los hechos que estudia "han pasado", ya se "han acabado", "están cerrados". Son fenómenos que no se dejan "formular con las expresiones establecidas" de la historiografía tradicional (Lyotard, 1988, 56). Al contrario, pareciese

6 Vid. Op. cit. en nota 5. 
como si estuvieran demandando nuevas categorías y nuevas técnicas de representación. Los acontecimientos modernistas son difíciles de asir, debido al hecho de que suturan la sacrosanta distinción entre el pasado y el presente, base tradicional de la historiografía tradicional. Los acontecimientos modernistas invaden el presente, que también se vuelve hacia ellos, obsesionado y traumatizado, atraido como por un abismo. De todas formas, el propio White considera que esta clase de acontecimientos no son irrepresentables o inefables (como podría serlo algún acontecimiento cósmico o incluso cuántico), ni en un sentido lingüístico ni en un sentido estético o artístico. La cuestión más importante es que requieren técnicas de representación diferentes a las usualmente aceptadas por la historiografía tradicional $(2003,241)$. O, en todo caso, son acontecimientos que requieren una mezcla de técnicas tanto "modernistas" como "tradicionales", tanto literarias (e, incluso, anti narrativistas) como "objetivistas". 7 Por eso, es de valorar la existencia de los nuevos intentos de la representación postmoderna, tanto los visuales como los textuales. En relación con estas cuestiones, W.G. Sebald ha escrito lo siguiente: "no creo que en la descripción de aterradores sucesos históricos tenga mucho sentido explayar este terror en cada página. El lector no está en condiciones de asimilarlo. El método siempre tiene que ser indirecto y tangencial, y se tiene que intentar dejar en claro a los buenos lectores - los hay - que el autor piensa siempre, o con mucha frecuencia, en el tema. Para mí, escribir este libro ha sido el intento de crear un museo alternativo del Holocausto. Aunque también es cierto que tan pronto algo terrible se ponga en un contexto estético, se convierte en conmensurable. Es el dilema moral de toda escritura". 8

Por otro lado, White también llama modernistas a los movimientos literarios y artísticos propios de finales del siglo XIX y comienzos del siglo XX, que comparten como característica común su oposición (o, en todo caso, su sospecha y su crítica) al plan modernista de una dominación de la naturaleza y de un control de la sociedad mediante la razón, la ciencia y la tecnología. También comparten un conjunto de técnicas novedosas de escritura y de representación. Estos movimientos literarios y artísticos ponen al servicio del historiador actual determinadas técnicas para representar esa clase de acontecimientos, "no naturales", que White considera distintivos del siglo XX, especialmente aquellos más traumáticos como el Holocausto, que han sido posibles gracias al progreso técnico-tecnológico. John Gray lo dice de una forma muy gráfica: "los pogroms son tan antiguos como la cristiandad, pero sin los ferrocarriles, el telégrafo y el gas venenoso no se podría haber producido ningún Holocausto" $(2008,25)$. Además, White considera que con estas representaciones modernistas se podría evitar la tentación del fetichismo de la historia tradicional, al que parecemos abocados cuando hacemos un uso exclusivo de técnicas de representación positivistas, "premodernistas" (2003, 246). Y es que la historiografía positivista parece como la plusvalía del pasado, centrada en los réditos y en las víctorias.

En términos de White, las representaciones modernistas (es decir, las representaciones historiográficas postmodernas, influídas por técnicas y estrategias provenientes de la literatura modernista), pueden facilitar la tarea del duelo, la tarea de elaborar y superar las heri-

7 En un lenguaje historiográfico y no literario, habría que hablar de técnicas postmodernistas y realistas, respectivamente.

8 W.G. Sebald: “Crecí en una familia posfascista alemana”, El País, 14 de julio de 2001 https:/elpais.com/ cultura/2016/10/27/babelia/1477566485_771964.html (22 de mayo de 2018). Agradezco a la profesora Gilda Bevilacqua la siguiente referencia. 
das y los traumas sufridos en un pasado reciente, una tarea que es individual pero también colectiva. Por eso White afirma que estas representaciones (o "experimentos historiográficos postmodernos" $"$ ) pueden tener un efecto terapéutico, porque pueden ayudar a controlar la ansiedad que el sufrimiento y la memoria de los traumas ocasionados por fenómenos como el Holocausto causan en las víctimas, en los supervivientes y en sus comunidades (el pasadoen-el-presente) (White, 2003, 245; y White, 2014, 61). Finalmente, pueden ayudarnos a percibir de una forma más adecuada los problemas del presente, lo cual juega en favor de las intenciones humanistas que el propio White asigna a la historiografía, incluida la postmoderna (el presente-en-el-pasado).

White se ha preguntado si hay algún límite para tramar de forma responsable acontecimientos "modernistas" como el Holocausto (que ya nos lo encontramos, en buena medida, elaborado y mediatizado, culturalmente, como un "hecho", con cierto contenido fáctico y con cierto significado) $(2003,37)^{10}$. Y ha planteado que las diferentes formas de tramar estos sucesos tendrían menos que ver con los acontecimientos en cuestión que con los diversos significados que el historiador dice encontrar en los "hechos" (aunque, en realidad, "construye" esos significados). Es decir, tendrían menos que ver con los acontecimientos (que dirían describir de forma realista y objetiva) que con las posturas ideológicas previas de cada historiador. En varios de sus trabajos, White ha defendido que la literatura puede representar el pasado de una forma tan idónea como la historiografía académica, ya que puede añadir a un interés característico de la historiografía tradicional por "lo real" del pasado, un interés literario por "la verdad" del pasado. "A veces incluso mejor que la historia profesional", como ha resumido Tozzi (2010a, 13).

Estudiando los elementos estilísticos distintivos de la llamada "literatura modernista"11 (de Proust, Joyce o Woolf a Adler, Sebald o Levi, pasando por Serraute, Beckett o RobbeGrillet), White llega a la conclusión de que las representaciones asociadas a este movimiento pueden mejorar, completar e, incluso, sustituir las posibilidades del realismo positivista clásico (digamos, académico y/o universitario). Entre las técnicas característicamente diferenciales de la literatura "modernista", se puede señalar la escritura intransitiva, como afirma Barthes, una característica distintiva de este movimiento literario respecto del realismo clásico, especialmente de ese realismo historiográfico de corte rankeano pero levantado sobre el estilo narrativo scottiano (2002, 23-33). Así, White subraya las posibilidades de unas técnicas muy concretas que pueden ser útiles para la historiografía académica y/o profesional: la "ocasión casual", el "monólogo interior", el "flujo de conciencia", el "tono de duda o cuestionamiento", o la "escritura intransitiva" y la "middle voice", que considera una forma adecuada para la representación de experiencias y de pensamientos ajenos porque permite que nos situémos en medio de distintas relaciones entre el tiempo y la vivencia del narrador, del autor y de los personajes históricos (Friedlander, 2007, 88; y Ricoeur, 2004, 530), tal

9 Por usar mi propia terminología, derivada de la obra de Munslow y Rosenstone, 2004.

10 En todo caso, White nunca ha afirmado que el conocimiento de la historia sea imposible, innecesario o inútil, sino que la historia no proporciona el mismo tipo de conocimiento que el conocimiento científico

11 Que es un "modernismo" no en el sentido de que "pertenezca" a la Modernidad (esa etapa de la historia que le sigue a la Edad Media) sino porque viene después de los intentos "modernos" de representar la realidad y la verdad del pasado: el realismo, el naturalismo, el historicismo, la novela histórica decimonónica, etc. Vid. White, 2014, 77-8. 
y como hace Noche y niebla de Resnais, Maus de Spiegelman o Borrados de Bartov. La escritura intransitiva intenta representar las tensiones entre algunos componentes del trabajo historiográfico que los historiadores han dado por definitivamente diferenciados: entre el presente y el pasado, cuya línea de demarcación siempre ha parecido, erróneamente, muy clara y distinta; entre el objeto y el sujeto, con la explicitación del componente emotivo, empático y afectivo del trabajo del historiador; o entre forma y contenido. Como ha escrito Paul, "intransitive writing simultaneously refers to what happened in the past and to what happens in the process of trying to represent a "past that does no go away" $(2011,135)$. Y como escribe White, el modernismo (y su continuación "post"), nos ha mostrado cuánto de construido, de ficcional y de imaginario "está contenido en lo que damos por "real" (2010a, 144). Este tipo de estrategia pone en marcha lo que Friedlander ha denominado "realismo alusivo o distanciado", para referirse al film de Lanzmann, Shoah $(2007,41)$; o lo que White llama "representación modernista", para referirse a varias obras como, por ejemplo, a las memorias de Levi, El sistema periódico.

Como escribe Snyder, nuestras representaciones del Holocausto deben permitirnos poder comprender e, incluso, poder experimentar lo que aún queda en el presente del nazismo, de Hitler y del genocidio judío $(2015,17)$. Porque el Holocausto no es solamente historia y memoria sino, fundamentalmente, advertencia, como han subrayado destacados pensadores como Mate, Baer o Forges (Mate, 2003; Baer, 2005; y Forges, 2006). White sugiere, además, que lo que él llama "Modernist Event" tiene un contenido, un referente y un substancia manifiesta: el trauma, producido en el pasado pero vivo en el presente $(2014,58)$. Sin embargo, como se ha subrayado en el volumen editado por Sobchack, "the effort to come to grips with the 'modernist event' can only take place in an atmosphere of historiographic doubt" $(2013,119)$. O, como afirma Jenkins, en una atmósfera intelectual en la que se aceptan los poderes liberadores de la aporía.

\section{El pasado práctico y el Holocausto}

Vivimos en un mundo de víctimas, en una sociedad de víctimas. Aunque, también, evidentemente, de verdugos. Y de espectadores (Gatti, 2006). Una sociedad donde las experiencias y los recuerdos de quienes han sufrido están intentando ocupar un espacio central en el debate público y académico. ${ }^{12}$ En este capítulo final voy a examinar algunas reflexiones importantes para comprender la postura ético-política de White respecto del papel de la historiografía en relación con el sufrimiento, la violencia y las víctimas, en general, así como respecto del Holocausto, en particular. Para ello, y antes de todo, me gustaría sugerir dos conclusiones provisionales.

En primer lugar, he seguido la distinción entre hechos y acontecimientos de White para subrayar la idea de que toda representación del pasado se construye bajo un punto de vista, el del historiador, que conceptualiza la información suministrada por las fuentes históricas en un todo del que no se puede predicar una correspondencia total y absoluta respecto de

12 En este sentido, con la labor todavía por hacer (tanto desde el punto de vista del derecho penal como del derecho penal internacional, del derecho humanitario o de las medidas de Justicia Transicional, por poner solo unos pocos ejemplos), me parece muy precipitada la critica de Daniele Giglioli, 2017. 
los hechos que dice describir o explicar (los "acontecimientos"). Aquí aparece la tan controvertida cuestión, estudiada por el propio White, y por buena parte de la historiografía analítica anglosajona, sobre el tramado de los hechos y sobre las respectivas narraciones de acontecimientos "entrelazados". Como explicaba White, una cosa es narrar (tramar una serie de hechos históricos, en base a los documentos o los testimonios disponibles) y otra narrativizar (creer que la narración expuesta en un libro de historia ha sido encontrada, tal cual, en los archivos). En este sentido, dicha distinción señala la naturaleza interpretativa e ideológica de nuestras representaciones sobre el pasado: tramar y narrar implican elegir un significado para un acontecimiento particular, un significado (trágico, épico, cómico, alegórico, irónico, etc.) que no se encuentra en los documentos custodiados en los archivos. ${ }^{13}$ De esta forma, como ha escrito Mate, "la historia es más bien una construcción moral en la que el ser humano busca respuesta a una pregunta que afecta al sentido de su vida" $(2018,125)$.

En segundo lugar, la concepción del acontecimiento modernista de White nos alerta de la nueva consciencia histórica en la que vivimos, una consciencia postmoderna que todavía ha de convivir con buena parte de la consciencia histórica moderna tradicional, académica y positivista. Una nueva consciencia que, además, ha de encontrar su plasmación en una nueva forma de representación historiográfica, alejada de lo que Ankersmit ha llamado la representación mimética o especular (basada en una supuesta correspondencia entre la realidad y el lenguaje) y más cercana a lo que se denomina representación "sustitutiva" del pasado (en la línea de Goodman, Gombrich o Danto). Como White no se ha cansado de repetir, el estudio del pasado nunca es inocente o neutral y nunca está desideologizado. Al contrario, toda forma de conocimiento histórico es producido desde una posición ideológica determinada y, por tanto, es usado para los intereses y las necesidades de esa ideología (anarquismo, conservadurismo, radicalismo o liberalismo, por ejemplo). Para los grupos subordinados, emergentes, de la periferia, olvidados y resistentes (es decir, para las víctimas), una historia elaborada, construida, a la manera tradicional (objetiva, neutral, imparcial, especializada, etc.) no sería sino una recomendación improductiva y, en la práctica, significaría un asimilación respecto de la ideología dominante en los estudios históricos desde finales del siglo XIX: el realismo positivista burgües y conservador (White, 1987: 81-2). La cuestión aquí es que "tener una historia", "pertenecer a la historia", es una de las dimensiones más importantes de la identidad individual y colectiva, de la cilización e, incluso, de lo que se considera humano, de la misma humanidad. Recordar y representar el pasado ("tener una historia") es la fuerza de la gravedad que va tensando y destensando el propio desarrollo identitario de las sociedades.

Por otro lado, la concepción de White sobre el "acontecimiento modernista" ofrece una solución de compromiso en el debate sobre la naturaleza del Holocausto como fenómeno histórico. En este sentido, White se posiciona a favor de nuestra capacidad para representar tal fenómeno, especialmente a través de las técnicas de la literatura modernista, incluida la "escritura intransitiva" y la "middle voice" que, en el fondo, no son sino dos cualidades intrínsecas de esa literatura modernista, en la que el escritor (el historiador) se hace presente en su discurso, explicitando su actividad, su implicación y sus límites (2011: 255-262 y 441-

13 White habla de 4 tipos de estructura narrativa o de tramado: el romance (o la novela), la comedia, la tragedia y la sátira. 
452). La conclusión, planteada por el propio White, es que las representaciones textuales, artísticas y visuales postmodernas pueden ayudarnos a enfrentar cuestiones históricas como el Holocausto e, incluso, pueden ayudarnos a desarrollar interpretaciones verídicas respecto de los acontecimientos ocurridos, por un lado, pero, también, fieles respecto de las experiencias vividas por las víctimas y por los supervivientes (experiencias de violencia, sufrimiento y trauma), y, por tanto, éticamente responsables (Okihiro, 2006, 161-172). Siendo fieles a los documentos y a los testimonios, las técnicas de la literatura modernista puede favorecer una historiografía que de cuenta de la complejidad multidimensional de un acontecimiento que ha dejado una herida colectiva tan intensa como el Holocausto. El propio Rorty ha escrito que "la novela, el cine y la televisión poco a poco, pero interrumpidamente, han ido reemplazando al sermón y al tratado como principales vehículos del cambio y del progreso moral" (1991, 18). Y ello es así porque estas técnicas artísticas nos ofrecen representaciones complejas y no clausurantes de las distintas formas de violencia y crueldad de las que somos capaces los seres humanos y, con ello, nos permiten ser conscientes de nuestra naturaleza, de lo que nos queda por hacer y de las distintas formas en que podríamos redescribirnos a nosotros mismos.

Por supuesto, una cosa es representar la crueldad y otra el sufrimiento. La representación del dolor, del sufrimiento y del trauma es un asunto mucho más complejo que representar la violencia. Ahí está la diferencia entre La lista de Schindler (1993) y Shoah (1985): la una se centra en mostrar la violencia mientras que la otra intenta desvelar el sufrimiento padecido (Sucasas, 2018). Y, como escribe Rees, "casi todo lo que nos encontramos es negativo. Comprobamos que, en este caso, el sufrimiento casi nunca es redentor" (2005, 28). Representar el Holocausto es contar una historia de degradación, de humillación y de depravación que podríamos considerar monstruosa, cuasi inhumana. Y una forma eficaz de evitar que se vuelva a producir otro Holocausto es concienciar a una sociedad para que desapruebe cualquier sentimiento de superioridad moral, racial o intelectual y para que no justifique ninguna clase de violencia, crueldad o sufrimiento.

La historiografía postmoderna, dice White, precisamente por las ansiedades textuales y profesionales que produce, nos puede enseñar que un pasado abierto, no clausurado, es lo máximo que podemos extraer de nuestras representaciones sobre los eventos modernistas: que "un pasado virtual es lo máximo a lo que podemos aspirar" $(2011,522)$. Y es que esto no es malo sino bueno. No necesitamos un "pasado histórico" sino un "pasado práctico". Es decir, una historiografía que sea más consciente de su naturaleza textual, constructivista e imaginativa. Es decir, una historiografía que pueda ponerse al servicio de otros intereses más plurales, democráticos y empáticos. Una comprensión más sofisticada y compleja del pasado nos puede ayudar a desarrollar una mayor y más amplia compasión. Una historiografía, como la postmoderna, que relaja su pretensión de objetividad y neutralidad, que subraya su naturaleza constructiva, textual y autoreferencial y que, por tanto, esté literaria y retóricamente informada, puede dejar de ser usada por las instituciones del poder y del estado para la creación mitificadora (es decir, parcial, acrítica, cuasi religiosa) de una identidad nacional y/o estatal. Así, una vez explicitadas las ansiedades que provoca la historiografía postmoderna (como las que pudiera provocar una visión histórica pragmatista como la que propone Rorty), el textualismo puede hacer el resto: socavar la autoridad científica y moral que se encuentra detrás de esa historiogafía decimonónica, postivista y objetivista, que pretendía estar describiendo y representando la verdad en sí, el noúmeno del pasado (White, 2011, 530). 
Como escribe White, "cada individuo y cada grupo tienen un pasado, por el hecho mismo de contar con algún tipo de herencia genética y cultural”. Pero la historia puede ser el pasado mismo y, a la vez, algo mucho más amplio y diferente. El pasado histórico es “creado por investigadores profesionales o de algún modo autorizados socialmente, a partir de lo que no es más que un pasado virtual hasta que es establecido como realmente sucedido, sobre la base de evidencias de un determinado tipo y autoridad" (White, 2010a, 124) que, por supuesto, no cubren el $100 \%$ de lo acaecido realmente. La historiografía tradicional también selecciona lo que ha de ser constituido como historia, en base a un conjunto de intereses académicos y políticos que, habitualmente, son conformados por los grupos dominantes de una sociedad (los llamados "vencedores"). La historia es vista como una disciplina desinteresada (objetiva y neutral). Es decir, la historiografía es vista como una disciplina científica "interesada", al menos potencialmente, en cualquier hecho o personaje históricos. Pero esto, en la práctica, no es así. Los historiadores seleccionan sus objetos de estudio y sus fondos documentales. Por no hablar de la tarea selectiva del propio Estado. White afirma que la historiografía tradicional suele ser un arma ideológica, en la medida en que "se duplica la opresión de los grupos ya vencidos, despojándolos de sus pasados históricos”, y, por tanto, también de sus identidades (2010a, 124). La perspectiva de White nos permite comprender que las sociedades postmodernas están en situación de realizar un compromiso con una historiografía más plural, que contenga la perspectiva de los "vencedores" pero, también, la de los "vencidos". Y ello no solamente en el caso paradigmático y ejemplar del Holocausto, donde, incluso, se le da más importancia, naturalmente, a la perspectiva de las víctimas y los vencidos. Por otro lado, este pasado histórico, profesionalmente constituido, solo existe en los libros (y, en menor medida, en una pequeña selección de representaciones historiográficas colectivas divulgadas mediante las llamadas Políticas de la Memoria, en el contexto de la educación, de la cultura histórica proporcionada por los mass media o en el contexto de las conmemoraciones y homenajes públicos sobre personas o acontecimientos del pasado). Podemos decir que las memorias colectivas son las representaciones mediante las cuales se comparte parte de la "memoria histórica" (es decir, los elementos "recordados" del pasado identitario) de las familias, los pueblos, los colectivos, las naciones y los países. Pero las memorias colectivas, debido a su interrelación con los marcos sociales de la memoria y debido a la permeabilidad respecto de las Políticas de la Memoria, también incluyen versiones simplificadas de ese pasado histórico profesionalmente constituido.

Sin embargo, hay otro pasado, el pasado que Oakeshott denominó "práctico", que es ese conjunto de fenómenos como la memoria, "trozos de información, fórmulas y prácticas que repetimos rutinariamente, e ideas vagas acerca de "la historia" de las que nos servimos" en nuestra vida diaria, para poder llevar a cabo distintas tareas y para vivir determinadas experiencias (White, 2010a, 125). White ha dicho que "el pasado práctico es el pasado de la memoria - individual y colectiva - y la utilidad que este tipo de conocimiento del pasado puede prestar. El pasado histórico es el pasado que se nos da en documentos, sobre todo en documentos que crean los grupos establecidos o dominantes. Las instituciones de hoy utilizan este pasado histórico para su propio beneficio. La situación es similar a la de grupos subalternos luego de que los colonizadores se fueran”. Sin embargo, White argumenta que este pasado subalterno "siempre ha sido criticado por los historiadores porque no está documentado. Pero este pasado práctico se estudia menos con el interés de descubrir 'lo que 
realmente ocurrió' que en comprender cómo las formas de vida presentes han sido dañadas por el trato que recibieron de los amos y que se han repetido en el presente como si fueran algo natural o estuvieran destinadas a serlo". ${ }^{14}$

La historia es una "memoria cultivada", una "memoria disciplinada", que pretende producir un pasado 'colectivo' a partir del cual se puede forjar, también, una identidad colectiva. Sin embargo, es la memoria, después de todo, la que nos obliga "a confrontar el enigma de cómo lo que ha sucedido en el pasado perdura en el presente" (White, 2011, 541). En un texto sobre la obra de Ricoeur, White escribe que la memoria, esa sensación de una presencia ausente, "es la base de la conciencia específicamente histórica, si bien la historia ha sido convencionalmente presentada como un correctivo para la memoria, o una aproximación más confiable al estudio del pasado que la "memorización"' (2011, 541-2). Y es que parece que la historia nos habla de lo que se recuerda (y de quién y para qué lo recuerda) mientras que la memoria nos pone sobre alerta acerca del olvido, acerca de lo que la historiografía ha olvidado. Al basarse sobre documentos, la historiografía tradicional "no trata de esos aspectos del pasado que la memoria experimenta como presencias ausentes que exigen ser recordadas (además de esperar justicia y una compensación) por la ofensas que las propias comunidades le infligieron a su humanidad" (2011, 546-7). La memoria nos confronta con las heridas de las sociedades, de los pueblos y de las naciones (Blake, 2008). Como no se ha cansado de repetir Todorov, la memoria no es un remedio infalible contra el mal de nuestras sociedades pero, sin ella, el mal en el mundo se puede reproducir impunemente puesto que el olvido del sufrimiento de las víctimas implica una muerte hermenéutica además de la muerte física $(2009,9)$.

Tanto la historiografía como las distintas ciencias sociales Occidentales "son más o menos útiles según la situación en que se encuentren" las comunidades que las producen (White, 2011, 531). White propone una historiografía que tenga una naturaleza terapéutica (como puede tenerla la psicología colectiva o la economía política, por ejemplo), un conjunto de "alternativas de representación no domesticadoras del pasado", en expresión de Tozzi (White, 2010a, 23), que nos permita enfrentar el pasado traumático reciente a la vez que nos permita imaginar futuros emancipadores y liberalizadores para nuestras sociedades. Para ello, la historiografía postmoderna nos da herramientas para que nos acostumbremos a la idea de que una multiplicidad de versiones respetuosas del pasado (como la que, en la práctica, ya existe), no es algo perjudicial sino, al contrario, es algo beneficioso, puesto que nos permite comprender las diversas dimensiones, los diversos intereses y los diversos actores implicados en el origen y en la evolución de una realidad que nació de la mano de la historiografía positivista: la nación y el estado contemporáneos (White, 2011, 532). El viejo motto de que la historia está escrita por los vencedores sintetiza muy bien esta vieja idea. Sin embargo, si queremos que el pasado no sea, simplemente, una cuestión teórica, "historiográfica" ("historical past"), sino, también, práctica ("practical past”), recuperando el componente ético y moral de la historiografía clásica, entendida como magistra vitae, entonces no nos sirve un relato genealógico ingenuo e inocente acerca del origen y de la evolución reciente de la (supuesta) pureza de sangre de nuestras comunidades, naciones, estados y países actuales. Igual que no existe una autobiografía sin errores, pasos en falso o daños colaterales, no existe una historiografía sin mácula, sin víctimas y sin sufrimiento.

14 Op. cit. en nota 5. 
De esta forma, vivimos un momento histórico que ha decidido volver la vista hacia las víctimas, hacia los perdedores, hacia los grupos subalternos. Y ha decidido empoderarlos. Y no solo por cuestiones emocionales relacionadas con el papel de las memorias colectivas sino, también, por motivos racionales e intelectuales de todo tipo. Frente a las razones de los vencedores, tenemos también la razón de los vencidos, el poder de los perdedores. Y, sobre todo, la empatía y la compasión para con las víctimas (que somos todos, de alguna manera u otra) de los procesos, de los acontecimientos y de los agentes históricos. Es el desarrollo de una especie de raison humanitaire lo que está en juego en este proyecto de una historiografía postmoderna y humanista como la que defiende White (Fassin, 2010), que no sea ajena a la influencia del existencialismo y del modernismo. De hecho, White nos recuerda que el papel de la historiografía debería ser ayudar al esfuerzo conjunto por liberarnos tanto de cualquier determinismo natural como de cualquier injusticia o discriminación social (2011, 497). En este sentido, la obra de White enlaza con la de LaCapra, cuando éste afirma que la única historiografía digna de ese nombre es la que conjuga una memoria crítica del pasado con una concepción del conocimiento histórico basada en documentos y textos que ayude a proyectos colectivos de búsqueda de la verdad, compasión y justicia (LaCapra, 2018, 114).

En suma, la historiografía postmoderna, en general, y la obra de White, en particular, nos recuerdan que más allá de los datos objetivos (que pueden ser "encontrados" en los archivos y descritos y explicados en las obras historiográficas), existe un marco interpretativo omnímodo e integral, que da sentido a la obra entera de un historiador. Y ese marco interpretativo es político, ideológico y, a la postre, estético (es decir, retórico, literario, ficcional). Es decir, que es una decisión est-ética (tener empatía y compasión) ponerse del lado de las víctimas del pasado para intentar representar su dolor, su sufrimiento y sus traumas. Como buena parte de Occidente ha venido haciendo, en las últimas décadas, para intentar comprender y representar el Holocausto. Parafraseando a Beristain, no cabe una historiografía de espaldas a Auschwitz y a lo que este acontecimiento representa: el papel fundamental de las víctimas para entender nuestro "presente extenso". Y el de su sufrimiento, para entender tanto su pasado como nuestro presente $(2004,41)$.

\section{Bibliografía}

Baer, A. (2005). El testimonio audiovisual: imagen y memoria del Holocausto. Madrid: CIS. Barthes, R. (2002). "Escribir, ¿un verbo intransitivo?”, en Barthes, R., El susurro del lenguaje. Barcelona: Paidós.

Barthes, R. (1984). "Le discours de l'histoire", en Barthes, Le bruissement de la langue. Essais critiques. París: Seuil.

Bauman, Z. (1997). Modernidad y Holocausto. Madrid: Sequitur.

Beristain, A. (2004). Protagonismo de las víctimas de hoy y mañana (Evolución en el campo jurídico penal, prisional y ético). Valencia: Tirant lo Blanch.

Blake, L. (2008). The Wounds of Nations: Horror Cinema, Historical Trauma and National Identity. Manchester: Manchester University Press.

Derrida, J. (2002). Schibboleth. Para Paul Celan. Madrid: Arena Libros.

Derrida, J. (2011). Seminario. La bestia y el soberano, Vol. II. Buenos Aires: Manantial.

Eagleston, R. (2008). The Holocaust and the Postmodern. Oxford: Oxford University Press. 
Erner, G. (2006). La societé des victimes. París: La Découverte.

Fassin, D. (2010). La raison humanitaire. Une histoire morale du temps présent. París: Gallimard-Sevil.

Forges, J.-F. (2006). Educar contra Auschwitz: historia y memoria. Barcelona: Anthropos.

Friedlander, S. (comp.) (2007), En torno a los límites de la representación. El nazismo y la solución final. Buenos Aires: Universidad Nacional de Quilmes.

Fritzsche, P. (2009). Vida y muerte en el tercer Reich. Barcelona: Crítica.

Gatti, G. (ed.) (2017). Un mundo de víctimas. Barcelona: Anthropos.

Giglioli, D. (2017). Crítica de la víctima. Barcelona: Herder.

Ginzburg, C. (2007). "Solo un testigo", en Friedlander, S. (comp.), En torno a los límites de la representación.

Gray, J. (2008). Perros de paja: Reflexiones sobre los humanos y otros animales. Barcelona: Paidós.

Jenkins, K. (1997). The Postmodern History Reader. London y New York: Routledge.

Korhonen, K. (ed.) (2006). Tropes for the Past: Hayden White and the History/literature Debate. Amsterdam y New York: Rodopi,.

LaCapra, D. (1983). Rethinking Intellectual History: Texts, Contexts, Language. Ithaca: Cornell University Press.

LaCapra, D. (2018). Understanding Others: Peoples, Animals, Pasts. Ithaca y London: Cornell University Press.

Langer, L.L. (1975). The Holocaust and the Literary Imagination. New Heaven: Yale University Press.

Lozano, Á. (2008). La Alemania Nazi (1933-1945). Madrid: Marcial Pons.

Lyotard, J.-F. (1988). The Differend: Phrases in Dispute. Minneapolis: University of Minnesota Press.

Lyotard, J.-F. (1997). Heidegger and "the jews". Minneapolis: University of Minnesota Press.

Mate, R. (2003). Memoria de Auschwitz. Actualidad moral y política. Madrid: Trotta.

Mate, R. (2018). El tiempo, tribunal de la historia. Madrid: Trotta.

Mayer, A.J. (1988). Why did the Heavens not Darken? The Final Solution in History. Nueva York: Pantheon Books.

Munslow A. y Robert A. Rosenstone (eds.) (2004). Experiments in Rethinking History. New York y Abingdon: Routledge.

Okihiro, L. (2006). "Divergence and Confluence, Maping the Streams of Hiroshima", en Korhonen, K. (ed)., Tropes for the Past.

Paul, H. (2011). Hayden White. Malden y Cambridge: Polity Press,.

Rees, L. (2005). Auschwitz: los nazis y la "Solución Final”. Barcelona: Crítica.

Ricoeur, P. (2004). Tiempo y narración II. Configuración del tiempo en el relato de ficción. Madrid: Siglo XXI

Rorty, R. (1991). Contingencia, ironía y solidaridad. Barcelona: Paidós.

Rovelli, C. (2016). La realidad no es lo que parece. Barcelona: Tusquets.

Sebald, W.G. (2001). "Crecí en una familia posfascista alemana”. El País, 14 de julio.

Snyder, T. (2015). Tierra negra. El Holocausto como historia y advertencia. Barcelona: Galaxia Gutenberg. 
Sobchack, V. (ed.) (2013). The Persistence of History: Cinema, Television and the Modern Event. London y New York: Routledge.

Sucasas, A. (2018). Shoah: El campo fuera de campo. Cine y pensamiento en Claude Lanzmann. Shangrila.

Todorov, T. (2009). La memoria, ¿un remedio contra el mal?. Barcelona: Arcadia.

White, H. (2014). The Practical Past. Evanston: Nortwestern University Press.

White, H. (2011). La ficción de la narrativa. Ensayos sobre historia, literatura y teoría 1957-2007. Buenos Aires: Eterna. Cadencia.

White. H. (2010a). Ficción histórica, historia ficcional y realidad histórica. Buenos Aires: Prometeo.

White, H. (2010b)."Postmodernism and Textual Anxieties", en White, H. The Fiction of Narrative. Essays on History, Literature, and Theory 1957-2007. Baltimore: The Johns Hopkins University Press.

White, H. (2009). "The Aim of Interpretation is to Create Perplexity in the Face of the Real: Hayden White in Conversation with Erlend Rogne". History and Theory, 48, , pp. 63-75.

White, H. (2003). El texto histórico como artefacto literario. Barcelona: Paidós.

White, H. (1995). "The Modernist Event and the Flight from History", en Hana Wirth-Nesher (ed.), The Sheila Carmel Lectures 1988-1993. Tel Aviv: Tel Aviv University Press.

White, H. ( 1988). "Historiography and Historiophoty", The American Historical Review, 93,5, p. 1194.

White, H. (1987). The Content of the Form. Baltimore y London: The Johns Hopkins University Press. 